\title{
TECHNOLOGICAL UNEMPLOYMENT: EDUCATING FOR THE FOURTH INDUSTRIAL REVOLUTION
}

\author{
MICHAEL A. PETERS \\ mpeters@waikato.ac.nz \\ University of Illinois, Urbana-Champaign; \\ University of Waikato
}

\begin{abstract}
.
This paper reviews recent the concerns and discussion about technological unemployment focusing on the trope "the robots are coming" and beginning with reference to the World Summit (2015) devoted to the issue. There is consensus that robots and big data systems will disrupt labor markets, kill jobs and cause social inequalities. The paper examines Klaus Schwab's concept of the "Fourth Industrial Revolution” - a concept that underlied the recent Davos meeting to inquire about the role of education in an age of automated cognition.

Keywords: Technological unemployment, robotization, job displacement, fourth industrial revolution, automated cognition, post-industrial education
\end{abstract}

For if every instrument could accomplish its own work, obeying or anticipating the will of others, like the statues of Daedalus, or the tripods of Hephaestus, which, says the poet, of their own accord entered the assembly of the Gods; if, in like manner, the shuttle would weave and

the plectrum touch the lyre without a hand to guide them, chief workmen would not want servants, nor masters slaves. --Aristotle (1985) Politics, trans. B. Jowett, in The Complete Works of Aristotle, ed. Jonathan Barnes, New Jersey: Princeton University Press, 1253b.

There is a prevailing opinion that we are in an era of technological unemployment - that technology is increasingly making skilled workers obsolete. --Mark MacCarthy (2014) Time to kill the tech job-killing myth, The Hill, http://thehill.com/blogs/congress-blog/technology/219224-time-to-kill-the-tech-job-killingmyth

1.

2.

3. 


\section{Introduction: The Robots are Coming}

The 2015 World Summit on "technological unemployment" held in New York September 8 by The World Technology Network (http://www.wtn.net/) in associated with IBM Watson and speakers such as Robert Reich, Larry Summers and Joseph Stiglitz addressed the issues by highlighting the new raft of disruptive technologies that will allegedly create jobless growth and world-wide unemployment:

Accelerating technological unemployment will likely be one of the most challenging societal issues in the 21st Century. Never before in history are so many industries being simultaneously upended by new technologies. Though "creative destruction," in which lost jobs are replaced with new ones, will be a factor, our newest technologies have the clear potential to eliminate many more jobs than we create. With technology advancing at a geometric pace, robotics, artificial intelligence, 3D-printing, and other innovations with enormous disruptive potential will soon hit the mainstream. Billions of people worldwide are currently employed in industries that will likely be affected-and billions of new entrants to the workforce will need jobs. http://www.wtn.net/technologicalunemployment-summit

Larry Summers (2014) writing for The Wall Street Journal suggests the main problem is not producing enough but providing enough work: "There are more sectors losing jobs than creating jobs. And the general-purpose aspect of software technology means that even the industries and jobs that it creates are not forever." His views are echoed by the current generation of economists.

Mark MacCarthy (2014) in "Time to kill the tech job-killing myth" acknowledges "There is a prevailing opinion that we are in an era of technological unemployment - that technology is increasingly making skilled workers obsolete." Yet in a contrary mood he is more optimistic choosing to emphasise the long-term relationship between technology and job creation focusing on the software industry that employs some 2.5 million directly and supports job growth in other industries ( 5 new jobs for every 10 software jobs).

Others are much less sanguine. Erik Brynjolfsson and Andrew McAfee in Race Against the Machine (2011) and The Second Machine Age (2016) have commented that the computer revolution has huge potential for disrupting labor markets and reducing labor costs. In their latest book they talk of the watershed in robotization and the corresponding increasing capacity and intelligence of digital technologies. Their empirical study led them to three 
broad conclusions. The first, hardly surprising or informative, is that "we're living in a time of astonishing progress with digital technologies-those that have computer hardware, software, and networks at their core.....” They go on to argue for a second conclusion that "the transformations brought about by digital technology will be profoundly beneficial ones...." The third conclusion is the one posing the greatest challenge:

digitization is going to bring with it some thorny challenges.... Rapid and accelerating digitization is likely to bring economic rather than environmental disruption, stemming from the fact thatas computers get more powerful, companies have less need for some kinds of workers. Technological progress is going to leave behindsome people, perhaps even a lot of people, as it races ahead (p. 11).

In an interview entitled "The Great Decoupling” McAfee suggests "Digital technologies are doing for human brainpower what the steam engine and related technologies did for human muscle power during the Industrial Revolution. They're allowing us to overcome many limitations rapidly and to open up new frontiers with unprecedented speed.” Brynjolfsson adds "Digital technologies allow you to make copies at almost zero cost. Each copy is a perfect replica, and each copy can be transmitted almost anywhere on the planet nearly instantaneously. Those were not characteristics of the First Machine Age, but they are standard for digital goods, and that leads to some unusual outcomes, such as winner-take-most markets." (https://hbr.org/2015/06/the-great-decoupling).

If the era of the Industrial Revolution was the First Machine Age, and Electicity the Second, then Electronics was the Third, and the Internet as plaform the Fourth.

In 2003 Marshall Brain wrote a series of articles on the coming robotic revolution. Over ten years later following the publication of Robotic Nation he notes the pace of automation has increased with advent of driverless cars, pilotless drones and automated retail systems like ATMs, restaurant kiosks, and self-service checkouts. These developsments emphasize the emergence of autonomous intelligent systems taking the form of humanoid robots. Moore's law CPU power doubles every 18 to 24 months or so and he documents Intel's release of the 4004 microprocessor in 1971 with a 4-bit chip running at 108 kilohertz and some 2,300 transistors, followed by the first IBM PC in 1981, Itel's first Pentium processor in 1993 (4.7 megahertz with 30,000 transitors), and the Pentium 4 with 1.5 gigahertz and 42 million transistors. Today supercomputers like the Milky Way-2 has in excess of 300 quadrillion FLOPS (floating operations per second). ${ }^{1}$ The iPhone 6 has more computing power than the Cray 2 supercomputers of the 1980s. 
Martin Ford (2009) in The Lights in the Tunnel: Automation, Accelerating Technology and the Economy of the Future argues that as technology accelerates machine automation may ultimately take over the economy creating significant job loss (up to $50 \%$ of all jobs in two decades) and a diminished discretionary income for the bulk of consumers.

Technological unemployment is undoubtedly an impending problem that will create greater inequalities and an increasing gap between the returns to labor and the returns to capital. There have been many proposed solutions to this problem including the Luddite strategy of refusing innovation, as well as more progression solutions based on the provision of welfare and public employment schemes and the introduction of a basic minimum income. Some economists have talked of granting subsidies and grants to small business and self-employed, the introduction of a shorter working week, and public ownership of the technolgocial infrstructure. In this general environment it seems increasingly unlikely that education by itself will be sufficient to solve problems of technological unemployment. ${ }^{2}$

\section{Klaus Schwab’s Fourth Industrial Revolution}

Klaus Schwab, the Founder and Executive Chairman, World Economic Forum wrote the underlying paper for the economic summit at Davos 2016 profiling what he calls “The Fourth Industrial Revolution”:

We stand on the brink of a technological revolution that will fundamentally alter the way we live, work, and relate to one another. In its scale, scope, and complexity, the transformation will be unlike anything humankind has experienced before. We do not yet know just how it will unfold, but one thing is clear: the response to it must be integrated and comprehensive, involving all stakeholders of the global polity, from the public and private sectors to academia and civil society. Schwab, 2016, http://www.weforum.org/agenda/2016/01/the-fourth-industrialrevolution-what-it-means-and-how-to-respond

He pictures the next industrial revolution as succeding the IT revolution of the 1970s that automated production and he speculates that a fourth revolution based on what he calls "cyber-physical systems" is the next development paradigm. First an era dominated by steam and mechanical production, what we commonly know as the industrial revolution, followed by the mass production paradigm that dominated the electric age, then IT and finally cyber-physical systems that can be seen as distinct era because of its velocity, scope and system impact. This is the age of global connections 
that have the power to transform entire systems of 'production, management, and governance.'

\title{
Navigating the next industrial revolution
}

\author{
Revolution Year Information \\ 11784 Steam, water, mechanical production equipment
}

21870 Division of labour, electricity, mass production

31969 Electronics, IT, automated production

$4 \quad$ Cyber-physical systems

The speed of technological 'breakthrough' Schwab argues has no historical precedent connecting billions of people through mobile devices that have unprecedented processing power, storage and unlimited access to knowledge. He writes: "And these possibilities will be multiplied by emerging technology breakthroughs in fields such as artificial intelligence, robotics, the Internet of Things, autonomous vehicles, 3-D printing, nanotechnology, biotechnology, materials science, energy storage, and quantum computing." (http://www.weforum.org/agenda/2016/01/the-fourthindustrial-revolution-what-it-means-and-how-to-respond).

What characterises the Fourth Industrial Revolution is the underlying digital logics that change everything. While it is the means for massive automation and the decline of industrial jobs it is itself not "industrial." This is what Schwab does not understand or theorize very well. An industrial technical system that had its beginnings in England and Scotland with the invention of a refined steam engine that could be applied to the textile industry has now been truly globalized but it is not just the extension of the scope and scale of industrialization that has changed. With each successive wave of technical innovation the logic has undergone fundamental changes in velocity, speed and scope with an accompanying emphasis on processes of abstraction, formalization, and mathematicization that enable and reward autonomous digital network systems.

Having reached its global limits of geography and the integration of world markets, it has increased the speed of its instant messaging and communication such that hundreds of thousands of transactions and 
information exchanges take place at the speed of light within the space of a micro-second. ${ }^{3}$ Today a single global technical system is emerging that connects and interlocks all major continents with some regionalisation in finance, commodities, news, communication and information. There is a single planetary technical system that enables access to global markets in instantaneous real time creating truly globally-scaled markets that dwarf the scale of the first industrial/colonial system and exponentially speeds up all transactions. A fundamental difference is that this single system perfected and refined reaching into every corner of the world no longer works on simple cause and effect and therefore is not linear but rather emulating natural systems becomes dynamic and transformative. This demonstrates the properties of chaotic and complex systems that also increase volatility, interconectivity and unpredictability. It is in part the consequence of the digital logic that drives the single technical system of "algorithmic capitalism." 4

Automated cognition is fundamental to digital capitalism. ${ }^{5}$ Braidotti (2015) suggests:

Automated cognition is central to today's capitalism. From the rationalization of labour and social relations to the financial sector, algorithms are grounding a new mode of thought and control. Within the context of this all-machine phase transition of digital capitalism, it is no longer sufficient to side with the critical theory that accuses computation to be reducing human thought to mere mechanical operations. As information theorist Gregory Chaitin has demonstrated, incomputability and randomness are to be conceived as very condition of computation. If technocapitalism is infected by computational randomness and chaos, therefore also the traditional critique of instrumental rationality has to be put into question: the incomputable cannot be simply understood as being opposed to reason. ${ }^{6}$

Others have provided a critique of "algorithmic ideology" as a means to understand corporate search engines and draw on algorithmic logics for their distributive power (Mager, 2014) and the different spatiotemporalities of automated trading that account for the speed of knowledge exploitation in financial markets (Grinstead, 2016). Ray Kurzweil's arguments that accelerating technology makes this unfolding era truly different especially with the facility of recursive self-improvement and the cumulative growth of $\mathrm{AI}^{7}{ }^{7}$ This is the age of genetics, nanotechnology and robotics that ushers in the age of singularity, enabling the rebuilding of the world molecule by molecule. 
Carl Frey and Michael Osborne's (2013) study examines how susceptible jobs are to computerization. Their empiricial work is quite detailed tracking the probability of computerisation for 702 detailed occupations. They argue: "about 47 percent of total US employment is at risk." They "provide evidence that wages and educational attainment exhibit a strong negative relationship with an occupation's probability of computerisation.” Their conclusion is worth refering to. They write:

While computerisation has been historically confined to routine tasks involving explicit rule-based activities (Autor, et al., 2003; Goos, et al., 2009; Autor and Dorn, 2013), algorithms for big data are now rapidly entering domains reliant upon pattern recognition and can readily substitute for labour in a wide range of non-routine cognitive tasks (Brynjolfsson and McAfee, 2011; MGI, 2013). In addition, advanced robots are gaining enhanced senses and dexterity, allowing them to perform a broader scope of manual tasks (IFR, 2012b; Robotics-VO, 2013; MGI, 2013). This is likely to change the nature of work across industries and occupations (p. 44).

They find that their model predicts job losses also in the service sector as well as transportation and logistics occupations, office and administrative support workers, and labour in production occupations. As they indicate "While nineteenth century manufacturing technologies largely substituted for skilled labour through the simplification of tasks... the Computer Revolution of the twentieth century caused a hollowing-out of middleincome jobs” (p. 45). These conclusions ought to be sobering for policy makers and educationalists alike: where will new jobs come from and what is the purpose for education especially at advanced levels when the covenant between higher education and jobs has been permanently broken? Frey and Osborne (2015) argue that the job stagnation in the digital age can only be avoided by a shift towards inclusive growth. How can higher education address inequalities brought on by technological change? With the expanding scope of automation will self-employment become the new normal? In relation to the prospect of transforming education they write:

While the concern over technological unemployment has so far proven to be exaggerated, the reason why human labour has prevailed relates to its ability to acquire new skills. Yet this will become increasingly challenging as new work requires a higher degree of cognitive abilities. At a time when technological change is happening even faster, a main hurdle for workers to adapt is thus the surging costs of education (p. 89). 
They note the surge in university fees and the spiralling student debt but argue that the same digital forces at work transforming the future of work can also transform education with the advent of MOOCS and virtual academies. They comment rather optimistically: "On campus lectures have no pause, rewind or fast-forward buttons, but MOOCs allow students to learn in ways that suit them the best. Students can skip some lectures while attending others several times at virtually no additional cost” (p. 90). Yet their account is uncritical of MOOCs and other forms of online learning that tend to follow the old industrial principles of one-to-the-many broadcast with little room for interaction and virtually no space as yet for the routine development of user content. ${ }^{8}$

The MOOCs revolution promises to open up school level and higher education by providing accessible, flexible, affordable courses, using a range of platforms. Fast-track completion of university courses for free or low cost has the potential to change course delivery, quality assurance and accreditation, credentialing, tuition fee structures and academic labour. Educational institutions need to learn from these initiatives and adopt new business, financial and revenue models to meet the needs of learners in an open marketplace. Open education brings opportunities for innovation and exploration of new learning models and practices. At the same time universities need to understand the threats of the monopolization of knowledge and privatization of higher education. By contrast they need to look to the prospects and promise of new forms of openness (open source, open access, open education, open science, open management) that promote "creative labor" and the democratization of knowledge (Peters, 2013d). Policy makers need to embrace openness and make education affordable and accessible and also profitable for institutions in an open higher education ecosystem (Peters \& Britez, 2008; Peters \& Roberts, 2011; Peters, Besley \& Araya, 2013).

Universities need to understand how four thousand years of linear writing is giving way to the tele-image and the ways in which digitization as an economic force holds sway over the cultural and the political. They need also to examine the evolution of new forms of collective intelligence (Levy, 2015; Peters, 2015) and their political innovations (Peters \& Heraud, 2015)-to mention a number of the immanent possibilities.

The digital revolution in and of itself will not transform education neccessarily for the good. What is required in addition to new digital technolgies and the emergence of massive digital systems that operate to centralise power is both political will and social vision to respond to the question: what is the role of higher education in the digital age when technological unemployment becomes the rule rather than the exception? 


\section{NOTES}

1. See http://pages.experts-exchange.com/processing-power-compared/

2. See Phillip Brown, Hugh Lauder and David Ashton (2011) The Global Auction: The Broken Promises of Education, Jobs and Incomes. See also https://www.youtube.com/watch?v=hyDVQpktyVY

3. See http://wpfdc.org/blog/economics/18793-speed-power-and-the-physics-offinance-capitalism

4. See http://www.truth-out.org/news/item/8887-algorithmic-capitalism-andeducational-futures-informationalism-and-the-googlization-of-knowledge

5. See Boutang's (2012) Cognitive Capitalism; Peters \& Bulut (2011) Cognitive Capitalism, Education and Digital Labour.

6. See http://cfh-lectures.hum.uu.nl/automated-cognition-algorithmic-capitalismand-the-incomputable/

7. See in particular Kurzweil's (2006) The Singularity is Near. See also http://thesingularityfilm.com/.

8. See "MOOCs and beyond: the politics of the post-industrial university" (Peters, 2013a); "The Revolution to Come: MOOCs and the Politics of the Postindustrial University” (Peters, 2013b); Massive Open Online Courses and Beyond: the Revolution to Come, http://www.truth-out.org/news/item/18120massive-open-online-courses-andbeyond-the-revolution-to-come (Peters 2013c); "The Development of Massive Open Online Courses (MOOCs) in New Zealand" (Gordon, Peters \& Besley 2015), https://akoaotearoa.ac.nz/download/ng/file/group5/development-of-moocs-in-nz.pdf

\section{REFERENCES}

Frey, C.A. \& Osborne, M.A. (2013) The Future Of Employment: How Susceptible Are Jobs To Computerisation? At http://www.oxfordmartin.ox.ac.uk/downloads/academic/The_Future_of_Employ ment.pdf

Frey, C.A. \& Osborne, M.A. (2015) Technology at Work: The Future of Innovation and Employment, at http://www.oxfordmartin.ox.ac.uk/downloads/reports/Citi_GPS_Technology_W ork.pdf

Grindsted, T.S. (2016) Geographies of high frequency trading - Algorithmic capitalism and its contradictory elements, Geoforum 68 (2016) 25-28.

Levy, P. (2015) Collective Intelligence for Education, Educational Philosophy and Theory, 47 (8): 749-754.

Peters, M.A. (2013b). "The Revolution to Come: MOOCs and the Politics of the Postindustrial University”, AARE Keynote, Monday 2 December 2013 at http://www.slideshare.net/mpt001/moocs-32200609 
Peters, M.A. (2013c). Massive Open Online Courses and Beyond: the Revolution to Come, http://www.truth-out.org/news/item/18120-massive-open-online-coursesandbeyond-the-revolution-to-come Saturday, 17 August 2013.

Peters, M.A. (2013d). Education, Science and Knowledge Capitalism: Creativity and The Promise of Openness. New York: Peter Lang.

Peters, M.A. (2015) Interview with Pierre A. Lévy, French philosopher of collective intelligence, Open Review of Educational Research, 2:1, 259-266, DOI: 10.1080/23265507.2015.1084477

Peters, M.A. \& Britez, R. (2008) (Eds.) Open Education and Education for Openness. Rotterdam \& Taipei, Sense Publishers.

Peters, M.A. \& Heraud, R. (2015) Toward A Political Theory Of Social Innovation: Collective Intelligence And The Co-Creation Of Social Goods, Journal of SelfGovernance and Management Economics, Volume 3(3), 2015, pp. 7-23.

Peters, M.A. and Roberts, P. (2011). The Virtues of Openness: Education, Science and Scholarship in a Digital Age. Boulder, Paradigm Publishers.

Peters, M.A., Besley, T., Araya, D. (2013) (Eds.) The New Paradigm of Development: Education, Knowledge Economy and Digital Futures. New York, Peter Lang.

Peters. M.A. (2013a). MOOCs and beyond: the politics of the post-industrial university. Paper presented at NZARE seminar, Wellington, July 8. 